\title{
Sivahari Theorem on odd and even integers
}

\author{
S. Haridasan \\ Kadayil house, Pampuram, Kalluvathukkal.P.O, Kollam, Kerala, India.
}

Squares of integers can be expressed as sum of consecutive odd numbers. Is there a general case for all powers? After a thorough search with available materials I could not find one such theorem. Here is an attempt in that lines. Sum of consecutive odd numbers as powers of integers and sum of consecutive even numbers also as powers of integers with formulae and simple proof.

\begin{tabular}{|c|c|c|}
\hline 1.1 & \multirow{2}{*}{\multicolumn{2}{|c|}{ 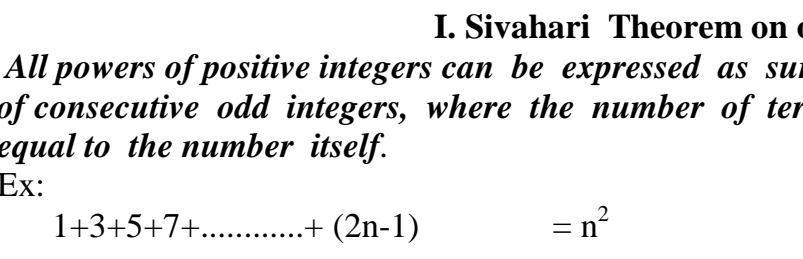 }} \\
\hline 1.2 & & \\
\hline 1.3 & $\begin{array}{l}1 \\
3+5 \\
7+9+11 \\
13+15+17+19 \\
21+23+25+27+29\end{array}$ & $\begin{array}{l}=1^{3} \\
=2^{3} \\
=3^{3} \\
=4^{3} \\
=5^{3}\end{array}$ \\
\hline 1.4 & $\begin{array}{l}1 \\
7+9 \\
25+27+29 \\
61+63+65+67 \\
121+123+125+127+129\end{array}$ & $\begin{array}{l}=1^{4} \\
=2^{4} \\
=3^{4} \\
=4^{4} \\
=5^{4}\end{array}$ \\
\hline 1.5 & $\begin{array}{l}1 \\
15+17 \\
79+81+83 \\
253+255+257+259 \\
621+623+625+627+629\end{array}$ & $\begin{array}{l}=1^{5} \\
=2^{5} \\
=3^{5} \\
=4^{5} \\
=5^{5}\end{array}$ \\
\hline
\end{tabular}

1.6 In general when $\mathrm{n}$ and $\mathrm{x}$ are positive integers

$\left[n^{x-1}-(n-1)\right]+\left[n^{x-1}-(n-3)\right]+\left[n^{x-1}-(n-5)\right]+\ldots \ldots \ldots \ldots \ldots . . . . .+\left[n^{x-1}+(n-3)\right]+\left[n^{x-1}+(n-1)\right]=n^{x}$

This formula will generate the required power and its sequence.

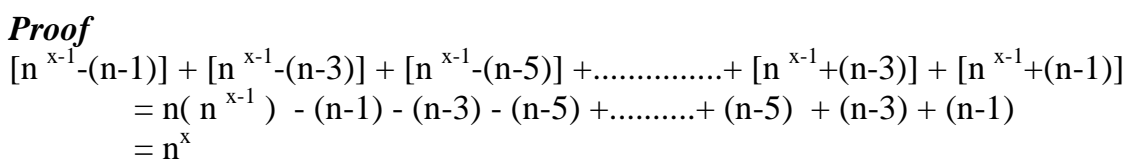

This can also be proved as an Arithmetic Progression with common difference 2 .

$$
\begin{aligned}
\text { Sn } & =\frac{(\text { first term }+ \text { last term }) \mathrm{n}}{2} \\
& =\frac{\left[\mathrm{n}^{\mathrm{x}-1}-(\mathrm{n}-1)+\mathrm{n}^{\mathrm{x}-1}+(\mathrm{n}-1)\right] \mathrm{n}}{2} \\
& =\mathrm{n} \cdot \mathrm{n}^{\mathrm{x}-1} \\
& =\mathrm{n}^{\mathrm{x}}
\end{aligned}
$$




\section{II.Sivahari Theorem on even integers}

2.1 For integers $n>1$ and $x=2$ all squares of numbers can be expressed as the sum of consecutive even integers minus that number, where the number of terms will be equal to the number itself.

$2.22+4+6+8+\ldots \ldots \ldots+2 n=n(n+1)=n^{2}+n$

2.3 For integers $n>1, x>2$ all powers of numbers can be expressed as sum of consecutive even integers plus that number, where the number of terms will be equal to the number itself.

2.4

$$
\begin{array}{ll}
2+4 & =2^{3}-2 \\
6+8+10 & =3^{3}-3 \\
12+14+16+18 & =4^{3}-4 \\
20+22+24+26+28 & =5^{3}-5 \\
6+8 & \\
24+26+28 & =2^{4}-2 \\
60+62+64+66 & =3^{4}-3 \\
120+122+124+126+128 & =4^{4}-4 \\
& =5^{4}-5
\end{array}
$$

2.5

2.6

$$
\begin{aligned}
& 14+16 \\
& =2^{5}-2 \\
& 78+80+82 \\
& =3^{5}-3 \\
& 252+254+256+258 \\
& =4^{5}-4 \\
& 620+622+624+626+628 \\
& =5^{5}-5
\end{aligned}
$$

2.7 In general for integers $\mathrm{n}>1$ and $\mathrm{x}>2$ we have,

$$
\left(n^{x-1}-n\right)+\left(n^{x-1}-n+2\right)+\left(n^{x-1}-n+4\right)+\ldots \ldots \ldots \ldots+\left(n^{x-1}+n-2\right)=n^{x}-n
$$

This formula gives the required power and its sequence.

\subsection{Proof}

Since this sequence represents an AP with common difference 2

$$
\begin{aligned}
S_{n} & =\frac{(\text { first term }+ \text { last term }) n}{2} \\
& =\frac{\left(n^{x-1}-n+n^{x-1}+n-2\right) n}{2} \\
& =\frac{\left(2 n^{x-1}-2\right) n}{2} \\
& =n \cdot n^{x-1}-n \\
& =n^{x}-n
\end{aligned}
$$

Hence the general theorem for odd and even integers.

\section{Bouddhayana Pearl Triplet}

For all integers $a, b, c>0$ triplets of the form $a^{2}+b^{2}=c^{2}$ converges to the single digit form $3^{2}+4^{2}$ $=5^{2}$ which can be named as Bouddhayana Pearl Triplet. Bouddhayana a great sage of the Vedic period mentions some of the well known triplets that constitute the sides of right angled triangles in his book Sulbasutra, the code of conduct of Vedic Sacrifices.

Trichatushkayoh 3,4,(5)

Dwadasikapanchikayoh 12, 5 , (13)

Saptika chaturvimsikayoh $7,24,(25)$. etc 
Ex; (1) Consider the triplet $\quad 7^{2}+24^{2}=25^{2}$

$$
\begin{aligned}
(4+3)^{2}+(20+4)^{2} & =(20+5)^{2} \\
4^{2}+2 \times 4 \times 3+3^{2}+20^{2}+2 \times 20 \times 4+4^{2} & =20^{2}+2 \times 2 \\
600+3^{2}+4^{2} & =600+5^{2} \\
3^{2}+4^{2} & =5^{2}
\end{aligned}
$$

Ex;(2) Another triplet $8^{2}+15^{2}=17^{2}$

$(5+3)^{2}+(11+4)^{2} \quad=(12+5)^{2}$

$5^{2}+2 \times 5 \times 3+3^{2}+11^{2}+2 \times 11 \times 4+4^{2}=12^{2}+2 \times 12 \times 5+5^{2}$

$264+3^{2}+4^{2}=264+5^{2}$

This is true for all integer solutions

$=5^{2}$

Let $\mathrm{a}_{1}^{2}+\mathrm{b}_{1}^{2}=\mathrm{c}_{1}^{2}$ be the single digit solution for $\mathrm{n}=2$.

If $x^{2}+y^{2}=z^{2}$ is a solution,

$$
\begin{aligned}
& \mathrm{x}=\mathrm{k}_{1}+\mathrm{a}_{1} \\
& \mathrm{y}=\mathrm{k}_{2}+\mathrm{b}_{1} \\
& \mathrm{z}=\mathrm{k}_{3}+\mathrm{c}_{1}
\end{aligned}
$$

Then $\left(\mathrm{k}_{1}+\mathrm{a}_{1}\right)^{2}+\left(\mathrm{k}_{2}+\mathrm{b}_{1}\right)^{2}=\left(\mathrm{k}_{3}+\mathrm{c}_{1}\right)^{2}$

$$
\begin{gathered}
\mathrm{p}_{1}+\mathrm{a}_{1}^{2}+\mathrm{p}_{2}+\mathrm{b}_{1}^{2}=\mathrm{p}_{3}+\mathrm{c}_{1}^{2} \\
\left(\mathrm{p}_{1}+\mathrm{p}_{2}\right)+\mathrm{a}_{1}^{2}+\mathrm{b}_{1}^{2}=\mathrm{p}_{3}+\mathrm{c}_{1}^{2}
\end{gathered}
$$

When $\mathrm{p}_{1}+\mathrm{p}_{2}=\mathrm{p}_{3}$ then $\mathrm{a}_{1}^{2}+\mathrm{b}_{1}^{2}=\mathrm{c}_{1}^{2}$

Also $\mathrm{a}_{1}^{2}+\mathrm{b}_{1}^{2}=\mathrm{c}_{1}^{2} \Rightarrow \mathrm{p}_{1}+\mathrm{p}_{2}=\mathrm{p}_{3}$

That means all integer triplets of the form $a^{2}+b^{2}=c^{2}$ converges to the single digit solution $3^{2}+4^{2}=5^{2}$. This can be extended to prove the general case of Fermat's Last Theorem.

\section{Acknowledgement}

I am greatly obliged to Dr. T.Thrivikraman Namboothiri, Former Professor and Head of Department of Mathematics, Cochin University of Science and Technology for the guidance in preparing this article. 